\title{
Risk for Low Pathogenicity Avian Influenza Virus on Poultry Farms, the Netherlands, 2007-2013
}

\author{
Ruth Bouwstra, ${ }^{1,2}$ Jose L. Gonzales, ${ }^{2}$ Sjaak de Wit, Julia Stahl, Ron A.M. Fouchier, Armin R.W. Elbers ${ }^{2}$
}

Using annual serologic surveillance data from all poultry farms in the Netherlands during 2007-2013, we quantified the risk for the introduction of low pathogenicity avian influenza virus (LPAIV) in different types of poultry production farms and putative spatial-environmental risk factors: distance from poultry farms to clay soil, waterways, and wild waterfowl areas. Outdoor-layer, turkey (meat and breeder), and duck (meat and breeder) farms had a significantly higher risk for LPAIV introduction than did indoor-layer farms. Except for outdoor-layer, all poultry types (i.e., broilers, chicken breeders, ducks, and turkeys) are kept indoors. For all production types, LPAIV risk decreased significantly with increasing distance to medium-sized waterways and with increasing distance to areas with defined wild waterfowl, but only for outdoor-layer and turkey farms. Future research should focus not only on production types but also on distance to waterways and wild bird areas. In addition, settlement of new poultry farms in high-risk areas should be discouraged.

A vian influenza is a disease of birds caused by influenza A viruses. Wild birds, particularly migratory water birds, form a natural reservoir of avian influenza viruses. Influenza viruses carry 2 glycoproteins on their surface, hemagglutinin (HA) and neuraminidase (NA), and on the basis of these glycoproteins are divided into subtypes. Eighteen distinct subtypes of HA (H1-H18) and 11 NA subtypes (N1-N11) have been described. Influenza A(H17N10) and $\mathrm{A}(\mathrm{H} 18 \mathrm{~N} 11)$, however, were recently detected in bats but not in birds. Virtually all remaining combinations of HA 1-16 and NA 1-9 subtypes have been isolated from wild birds (1). Wild birds pose a special risk for introducing avian influenza viruses of all subtypes to poultry kept in free-range or outdoor facilities (2).

Avian influenza virus infections in wild birds usually are asymptomatic. Infection of poultry ranges from no

Author affiliations: Wageningen Bioveterinary Research,

Lelystad, the Netherlands (R. Bouwstra, J.L. Gonzales,

A.R.W. Elbers); GD Animal Health, Deventer, the Netherlands

(S. de Wit); Sovon Dutch Center for Field Ornithology, Nijmegen, the Netherlands (J. Stahl); Erasmus Medical Center, Rotterdam,

the Netherlands (R.A.M. Fouchier)

DOI: https://doi.org/10.3201/eid2309.170276 disease to severe disease and up to $100 \%$ mortality (3). A virus that causes no or mild disease in chickens is considered a low pathogenicity avian influenza virus (LPAIV); a virus that causes high rates of death in chickens is considered a highly pathogenic avian influenza virus (HPAIV) (4). HPAIV outbreaks in poultry cause huge direct and indirect economic losses (5). Furthermore, on several occasions during the last decade, bird-to-human transmissions of $\mathrm{H} 5, \mathrm{H} 6, \mathrm{H} 7, \mathrm{H} 9$, and $\mathrm{H} 10$ virus subtypes have occurred, emphasizing the threat to public health worldwide (6). Every HPAIV described has belonged to $\mathrm{H} 5$ and $\mathrm{H} 7$ subtypes and, until the spread of the Asian HPAIV subtype H5N1 to other parts of the world by wild birds since 2005 (7), mainly emerged after LPAIV of these subtypes were introduced in poultry, particularly in chickens and turkeys (8). Therefore, LPAIV of the H5 and H7 subtypes is notifiable to the World Organisation for Animal Health; consequently, member states of the European Union have implemented surveillance programs (9).

In the Netherlands, passive and active surveillance programs are in place. In the active serologic surveillance program, all poultry farms are tested 1-4 times a year. Frequency of sampling differs among poultry types (indoorand outdoor-layer chickens, chicken breeders, broilers, ducks, and turkeys) and housing systems based on the supposed differences in the risk for LPAIV introduction. Except for outdoor-layers, all poultry types are kept indoors.

In a previous study (10), a significantly higher risk for LPAIV introduction was observed on poultry farms in Europe housing Anseriformes (duck, geese, and game birds) than on farms housing Galliformes (chicken breeders, broilers, layer chickens, and turkeys), and no significant differences were observed among Galliformes. In addition, Gonzales et al. (11) reported a significantly higher risk for LPAIV introduction on outdoor-layer, turkey, duck-breeder, and meat-duck farms than on indoor-layer farms in the Netherlands using surveillance data for 2007-2010. These studies $(10,11)$ did not find differences in the risk for introduction among farms keeping chickens indoors, particularly between

\footnotetext{
${ }^{1}$ Current affiliation: GD Animal Health, Deventer, the Netherlands. ${ }^{2}$ These authors contributed equally to this article.
} 
layers and broilers, possibly because of the limited data on positive introductions (or zero introductions) into broiler farms (11), which compromised the power of the comparisons. Our objective was to update the risk analysis of introduction of LPAIV infection using an extended surveillance period (2007-2013) and add spatial-environmental factors to the analysis that might explain part of the variation in LPAIV introductions on poultry farms in the Netherlands.

\section{Materials and Methods}

\section{Data}

We analyzed all data from the Netherlands' surveillance program collected during January 2007-December 2013. In the Netherlands, 3 types of surveillance programs are used to detect avian influenza virus infections on commercial poultry farms: passive surveillance, early warning, and serologic monitoring.

Passive surveillance for the early detection of notifiable avian influenza is based on clinical signs (12), an anamnesis of exponentially increasing death in the affected flock, or both. This surveillance is effective for acute infection causing severe disease (mainly HPAIV infection) but less so for LPAIV infection, which often causes mild or no disease. Samples (blood, tissue, and/or tracheal and cloacal swabs) of diseased/dead birds are tested by ELISA, PCR, and virus isolation.

Early warning includes signals such as aberrations in production parameters (decreased egg production, increased death rates, decreased feed and/or water intake). It excludes avian influenza as the cause of clinical problems in poultry flocks in situations in which birds show clinical signs that can be caused by other avian pathogens. Tracheal and cloacal swabs are tested for avian influenza by PCR (exclusion diagnostics).

The serologic monitoring program is active surveillance to detect all avian influenza virus incursions, even those that remain subclinical. This program is much more intense than required by the European Union: all poultry farms, except outdoor-layer farms and turkey farms, are tested at least once a year. Thirty samples per farm are screened by ELISA, and positive samples are confirmed by hemagglutination-inhibition test. Outdoor-layer farms are tested 4 times per year, and turkey farms are tested each production cycle. Meat-turkey farms have an average production cycle of $\approx 4$ months; for broilers and meat ducks, this cycle is $5-6$ weeks. All sampling is done just before slaughter, except the 3 extra samplings in outdoor-layer farms.

Farms were identified by their unique farm number and categorized on the basis of poultry production type (PT): duck breeders, meat ducks (meat production), turkey breeders, meat turkey, broilers, broiler breeders, indoorlayers, outdoor-layers, and layer breeders.
We selected putative spatial-environmental risk factors for LPAIV introduction related to farm location for incorporation in the risk model. These risk factors were distance to clay soil, distance to waterways, and distance to defined wild waterfowl areas.

We analyzed the farms' distance to clay soil (Geodesk database [GDB3]; Wageningen University, Wageningen, the Netherlands). Clay soil is a sediment of large rivers and is, in epidemiologic terms, a proxy for the presence of large water quantities, which is a proxy for an attractive environment for wild waterfowl. Wild waterfowl is presumed to be the most important reservoir for LPAIV. Presence of clay soil close to poultry farms was a risk factor for LPAIV introduction on outdoor-layer farms (13).

We also assessed distance from farms to waterways. Three sizes of waterways (width in meters) were included in the model: small (0.5-3 m wide), medium (3-6 $\mathrm{m}$ wide), and large ( $\geq 6 \mathrm{~m}$ wide). Presence of waterways is a proxy for an attractive environment for wild waterfowl; spatial data of waterways was available from the Dutch Land Registry (http:// www.kadaster.nl/web/artikel/producten/TOP10NL.htm).

Distance to defined wild waterfowl areas is a direct proxy for a possible avian influenza virus reservoir. Wild waterfowl areas were defined as follows: areas with on average $\geq 5$ wild water birds counted per hectare (based on systematic regular bird census schemes by Sovon [Nijmegen, the Netherlands], which coordinates the monitoring of wild bird populations in the Netherlands). Birds of the families Anatidae, Laridae, and Rallidae were included; these birds are known avian influenza virus carriers $(14,15)$ (online Technical Appendix, https://wwwnc.cdc.gov/EID/ article/23/9/17-0276-Techapp1.pdf).

\section{Positive Farms}

Positive farms were defined as follows: farms with $\geq 1$ seropositive animal to any avian influenza strain in both the screening ELISA (IDEXX FLockCheck AI MultiSScreen, IDEXX Europe B.V., Hoofddorp, the Netherlands) and the confirmatory hemagglutination-inhibition test; or farms with $\geq 3$ positive results (of 30 serum samples) in the screening ELISA. Furthermore, we included in the analysis only primary cases (excluding secondary spread detected by epidemiologic tracing).

\section{Period at Risk}

\section{Positive Farms}

For every year, we estimated the period at risk (in months) as the sum of the period from January 1 and the last negative sampling plus half of the period between the last negative sampling and the positive sampling. In case of no negative sampling in the year the farm became positive, the last negative sampling of the year before was included. In that 
instance, the time at risk was estimated as half of the period from the last negative sampling to the first positive sampling. Broilers, meat turkeys, and meat ducks were sampled 1 week before the end of their production. Therefore, the period at risk for these PTs was set at a fixed period.

\section{Negative Farms}

For every year, we estimated the period at risk (in months) as the period from January 1 through last negative sampling. This sampling was done for all PTs except broiler, meat-turkey, and meat-duck farms. For the latter, the period at risk was the same as for the corresponding positive farms.

\section{Statistical Analysis}

We analyzed data using the statistical software $\mathrm{R}$ version 3.1.3 (https://www.r-project.org/). The relative risk (RR) of introduction of LPAIV per type of poultry farm (PT), during the study period (2007-2013) was quantified using multivariate statistical models (known as generalized linear models or generalized linear mixed models [GLMMs]) (online Technical Appendix). We used indoor-layer chicken farms as the reference category. In terms of disease causation, if the $R R$ is $<1$, the factor is considered a sparing factor, whereas if the $R R$ is $>1$, the factor is considered a putative causal factor (16). In addition, we studied the effect of the spatial-environmental variables (distance to clay soil, waterways, and wild waterfowl areas) on the risk for LPAIV introduction. Statistical investigation started with a univariate analysis; distance of clay soil to the location of poultry farms was significantly associated with risk for LPAIV introduction only for layer (indoor and outdoor) farms. The different categories of waterways were significantly associated with risk for LPAIV introduction, but medium-sized waterways showed by far the strongest association. Thus, in the multivariate analysis, distance to clay soil and small- and large-sized waterways fell out of the model in the selection process; distance to medium-sized waterways and distance to wild waterfowl areas were strongly associated with risk for LPAIV introduction and stayed in the model when tested together in the multivariate analysis.

\section{Results}

During 2007-2013, we surveyed 19,274 farms and detected 295 LPAIV introductions (Table 1). The Netherlands has a small population of turkey and duck breeder farms, and these small populations, in particular turkey breeders (only 1 farm in 2013 and a maximum of 5 in 2007), made it difficult to evaluate potential interactions (e.g., between PT and distance variables) when modeling the risk for introduction. Therefore, we first made an overall quantification of the RR for each PT and included the year of surveillance as a random effect in a GLMM. Broiler, broiler-breeder, and layer-breeder farms were at significantly lower risk for LPAIV introduction $(\mathrm{p}<0.05)$ than were indoor-layer farms (e.g., broiler farms had on average a 5 times [1/0.2] lower risk for LPAIV introduction than did indoor-layer farms) (Table 2). By contrast, the risk was significantly higher for outdoor-layer, duck, duck-breeder, meat-turkey, and turkey-breeder farms $(\mathrm{p}<0.05)$ (e.g., outdoor-layer farms had on average a 6.3 times higher risk for LPAIV introductions than indoor-layer farms). The effect of distance from medium-sized waterways to farm location was comparable for the different PTs, and we included this variable in the GLMM (Table 2). The risk for LPAIV introduction decreased with increasing distance from poultry farms to medium-sized waterways; RR was highest within the closest $500 \mathrm{~m}$ (Figure 1). To evaluate potential statistical interactions, we combined meat-turkey and turkey-breeder farms (which had similar RR estimates in our first analysis [Table 2]), and we evaluated the effect of the location variables and potential interactions. A generalized linear model fit better than a GLMM. We identified significant interactions between 1) year of surveillance and indoorand outdoor-layer farms and 2) distance to wild waterfowl areas and outdoor-layer farms or meat turkey farms. The analysis showed a yearly decrease in the RR for indoorlayer farms (Table 3), in contrast to an increased risk for

\begin{tabular}{|c|c|c|c|c|c|c|c|}
\hline Type of farm & $\begin{array}{l}\text { No. farms } \\
\text { positive }\end{array}$ & $\begin{array}{l}\text { Total no. } \\
\text { farms }\end{array}$ & $\begin{array}{l}\text { Median time } \\
\text { at risk, mo }\end{array}$ & $\begin{array}{l}\text { Median distance to wild } \\
\text { water bird areas, } \mathrm{m}\end{array}$ & $\begin{array}{l}\text { Median distance to medium- } \\
\text { sized waterway, m† }\end{array}$ & $\begin{array}{l}\text { Probability of } \\
\text { introduction } \ddagger\end{array}$ & $\mathrm{RR} \S$ \\
\hline Indoor-layer & 60 & 5,600 & 7.3 & 4,227 & 769 & 0.001 & 1 \\
\hline Outdoor-layer & 143 & 2,549 & 6.3 & 3,996 & 670 & 0.009 & 6.0 \\
\hline Layer-breeder & 14 & 2,174 & 9.5 & 4,157 & 738 & 0.001 & 0.5 \\
\hline Broiler & 2 & 5,409 & 1.2 & 3,292 & 576 & 0.000 & 0.2 \\
\hline Broiler-breeder & 14 & 2,718 & 8.5 & 4,002 & 824 & 0.001 & 0.4 \\
\hline Meat-turkey & 30 & 469 & 3.7 & 3,208 & 1,042 & 0.017 & 11.7 \\
\hline Turkey-breeder & 2 & 18 & 5.7 & 2,035 & 659 & 0.019 & 13.1 \\
\hline Meat-duck & 16 & 267 & 1.2 & 3,477 & 1,180 & 0.050 & 33.9 \\
\hline Duck-breeder & 14 & 70 & 5.8 & 4,107 & 767 & 0.034 & 23.4 \\
\hline
\end{tabular}

*LPAIV, low pathogenicity avian influenza virus; RR, relative risk.

†Distance to clay soil and distance to small- and large-sized waterways also included in the multivariate analysis (data not shown). They did not have a significant effect on the risk for LPAIV introduction. Waterway sizes were defined as follows: small, 0.5-3 m wide; medium, 3-6 m wide; large, >6 m wide. ‡Unadjusted probabilities of LPAIV introduction per farm months at risk.

$\S$ These are the unadjusted RR estimates obtained by dividing the unadjusted probabilities of LPAIV introduction of each type of poultry farm by that of indoor-layer farms. 
Table 2. Relative risks for introduction of low pathogenicity avian influenza virus infection in different types of poultry farms, the Netherlands, 2007-2013

\begin{tabular}{lcc}
\hline Type of poultry farm & Relative risk $(95 \% \mathrm{Cl})$ & $\mathrm{p}$ value \\
\hline Indoor-layer & $1.0($ reference) & \\
Outdoor-layer & $6.3(4.7-8.6)$ & $<0.00001$ \\
Layer-breeder & $0.5(0.3-0.8)$ & 0.008 \\
Broiler & $0.2(0.1-0.8)$ & 0.02 \\
Broiler-breeder & $0.4(0.2-0.8)$ & 0.004 \\
Meat-turkey & $12.0(7.8-18.8)$ & $<0.00001$ \\
Turkey-breeder & $11.3(2.8-46.2)$ & 0.0008 \\
Meat-duck & $39.5(22.6-69.1)$ & $<0.00001$ \\
Duck-breeder & $25.5(14.2-45.9)$ & $<0.00001$ \\
Natural logarithm* & $0.8(0.7-0.9)$ & 0.00005 \\
\hline *Of distance to medium-sized waterways in meters, i.e., 3-6 m wide.
\end{tabular}

outdoor-layer farms for 2012 and 2013 (Figure 2). The risk for LPAIV introduction in outdoor-layer and meat turkey farms decreased with increasing distance to areas with wild waterfowl (Figures 2, 3). No significant risk was found for distance to clay soil.

\section{Discussion}

Our study shows that outdoor-layer, duck (breeder and meat), and turkey (breeder and meat) farms have a significantly higher RR for LPAIV introduction than do indoorlayer farms. The higher risk in outdoor-layer farms probably reflects their higher exposure to LPAIV from a contaminated environment. The presence of avian influenza in wild water birds and the frequency of direct or indirect contact between reservoir birds and poultry are risk components that enable transmission from wild birds to poultry. However, in addition to the higher introduction rate on outdoorlayer farms (this study) and the genetic relationship of wild

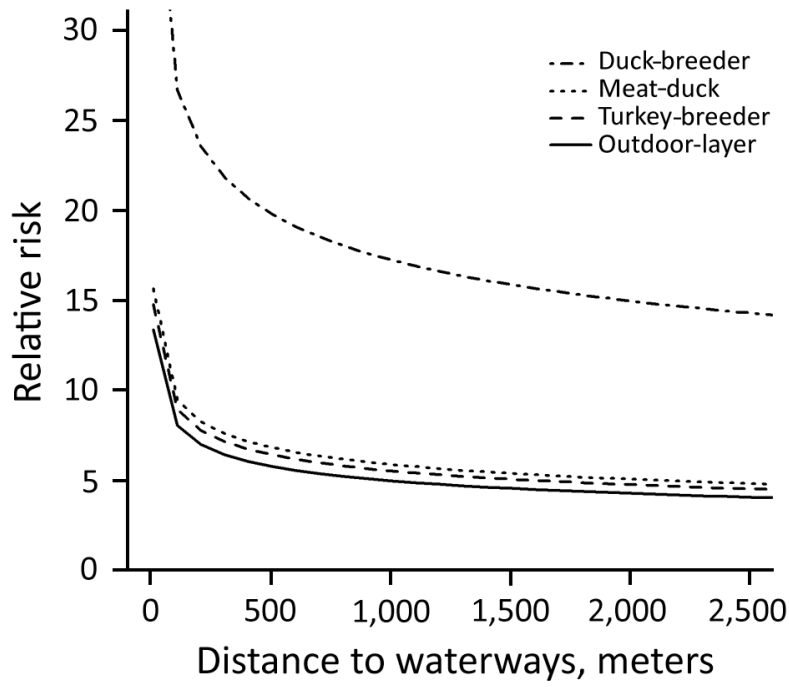

Figure 1. Risk for introduction of low pathogenicity avian influenza virus into duck-breeder, meat-duck, meat-turkey, and outdoor-layer farms, the Netherlands, 2007-2013. For the estimation of the relative risk as a function of distance to medium-sized waterways (3-6 m wide), distance to wild waterfowl areas was kept constant. bird strains and avian influenza outbreak viruses (17), no scientific data have been available that could support this assumption, although physical environmental factors, such as surface water availability and proximity to lakes and wetlands, have been suggested as drivers of HPAIV H5N1 outbreaks in poultry and wild birds $(18,19)$.

We described a significant spatial-environmental relationship: the closer to waterways - a proxy for an attractive environment for wild waterfowl - and wild waterfowl areas a farm is located, in particular outdoor-layer farms, the higher the risk for LPAIV introduction. Although waterfowl and shorebirds are known to form the major natural reservoir and source of all known influenza A viruses $(14,20,21)$, there is little direct evidence for transmission of avian influenza virus from (wild) birds to poultry. Two lines of evidence suggest that wild birds can be the source of avian influenza infection in poultry: 1) temporal associations between avian influenza virus isolated from wild birds and from outbreaks in poultry flocks and 2) genetic similarity between avian influenza virus strains isolated from wild birds and from poultry. Phylogenetic studies support the presumed transmission route from wild birds to poultry. For example, an LPAIV H7N7 caused the HPAI H7N7 epidemic in the Netherlands that started at a free-range farm (22). This virus is believed to be a reassortant of an $\mathrm{H} 7 \mathrm{~N} 3$ virus and an H10N7 virus isolated from mallards in 2000 during survey studies of migratory wild birds in the Netherlands (23). Furthermore, recent genetic analyses of HPAIV H5N8 strains from the Netherlands, and of other strains from countries in Europe, South Korea, and Japan, suggested that the strains from Europe probably arrived through migratory wild birds from Asia, most likely through overlapping flyways and common breeding sites in Siberia $(24,25)$.

In the Netherlands, turkeys are raised indoors, and despite the small number of turkey farms, we observed a higher RR for introduction of LPAIV infection to breeder and meat-turkey farms. This higher risk might be associated partly with the apparent higher susceptibility of turkeys than chickens to LPAIV infection (26).

As reported by Gonzales et al. (10), we found that duck-breeder farms have the highest RR for LPAIV introduction. This risk could be related to their higher susceptibility to infection with LPAIV of wild water bird origin (ducks, geese, and swans) than chickens (27) and

\begin{tabular}{lc}
\hline $\begin{array}{l}\text { Table 3. Yearly relative risk for introduction of low pathogenicity } \\
\text { avian influenza virus in indoor-layer farms, the Netherlands }\end{array}$ \\
\hline Year & Relative risk (95\% Cl) \\
\hline 2007 & 1 (reference) \\
2008 & $0.65(0.48-1.04)$ \\
2009 & $0.63(0.28-0.84)$ \\
2010 & $0.41(0.28-0.68)$ \\
2011 & $0.56(0.44-0.70)$ \\
2012 & $0.5(0.30-0.83)$ \\
2013 & $0.15(0.04-0.27)$ \\
\hline
\end{tabular}




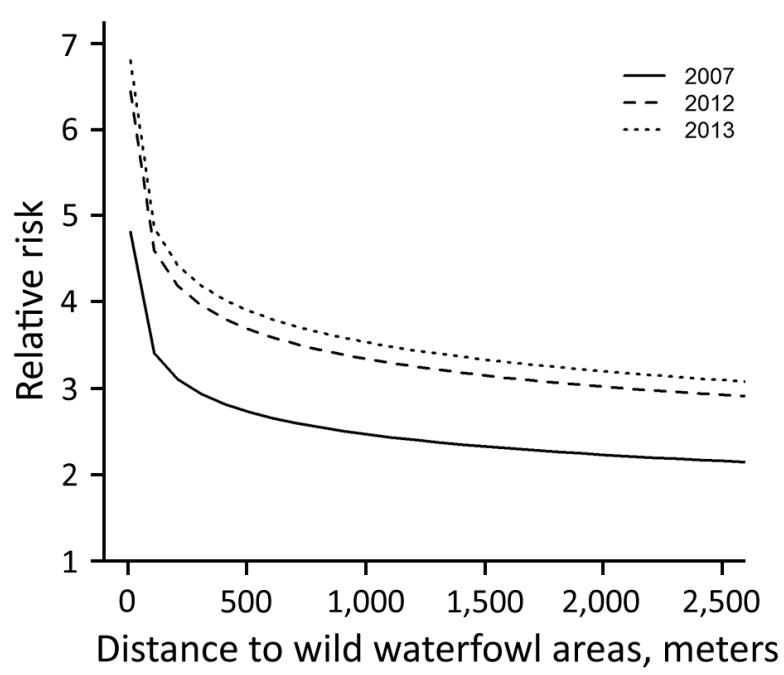

Figure 2. Risk for introduction of low pathogenicity avian influenza virus into outdoor-layer farms, the Netherlands, 2007-2013. Relative risk is shown for 2007 (reference for between-year comparison), 2012 ( $p=0.08)$, and 2013 ( $p=0.005)$. For the estimation of the relative risk as a function of distance to wild waterfowl areas, distance to medium-sized waterways (3-6 m wide) was kept constant.

their long production cycle (time of exposure). We also observed a significantly higher risk for LPAIV introduction into meat-duck farms than into indoor-layer farms. This finding is somewhat surprising because meat ducks are kept indoors and have a short production cycle (6.5 weeks), in contrast with broilers, which also are kept indoors, have a short production cycle (6 weeks), and had a very low risk for LPAIV introduction. The higher susceptibility of ducks than chickens to LPAIV (27) could be a reason to explain this contrast. In addition, poor biosecurity compliance might play a role. For instance, floor bedding for ducks is stored outside (often not protected by a cover) and transported inside the duck house several times during the growing period. Bedding material for broilers is mostly stored inside the poultry house and is placed only once during the production cycle or not replaced. Poor biosecurity compliance has been reported repeatedly in poultry production $(28-30)$. Meat ducks and broilers are tested before slaughter, and considering that the time to build up a serologic prevalence after an LPAIV infection that can be detected by random sampling could take $\approx 2-3$ weeks (31), LPAIV introductions that occur shortly before slaughter could be missed. Therefore, the RRs could be underestimated for both meat ducks and broilers. Nevertheless, by looking at the large number of broiler flocks tested along these years, the fact that only 2 LPAIV introductions were detected, and the fact that surveillance was able to detect a relatively high number of LPAIV introductions in meat ducks (also short production cycle), we conclude that the risk for LPAIV introduction in broilers is low under housing conditions in the Netherlands.

In addition, the RR for layer-breeder farms was 5 times lower for LPAIV introduction than it was for indoor-layer farms (2011-2013). These findings might be related to the high biosecurity levels on these PTs.

Our finding that the RR for LPAIV introduction on outdoor-layer farms increased over time (a significantly higher RR in 2013 than in 2007, 2008, 2009, and 2011) can be explained by an increase of the number of introductions on outdoor-layer farms, especially in 2012 and 2013. An increase in the number of outdoor-layer farms and a decrease in the number of indoor-layer farms (for which RR decreased over time), particularly in 2012 and 2013, might partly explain these changes in risk. Further research is needed to gain insight into the factors that might affect introduction rates and differences over time. A plausible explanation might be increased direct or indirect contact between outdoor ranging poultry and infectious wild bird populations, but this explanation remains speculative because field data on the type and frequency of contact between wild birds and poultry in outdoor-layer farms is still missing. Climate and land use changes during the past decades have affected winter and breeding bird community composition (32); effects on herbivorous birds (such as many waterfowl species) through phenology-induced changes of plant forage quality and availability are most pronounced $(33,34)$.

As recent experience shows, wild birds can introduce HPAIV directly into poultry $(24,25)$, and HPAIV can

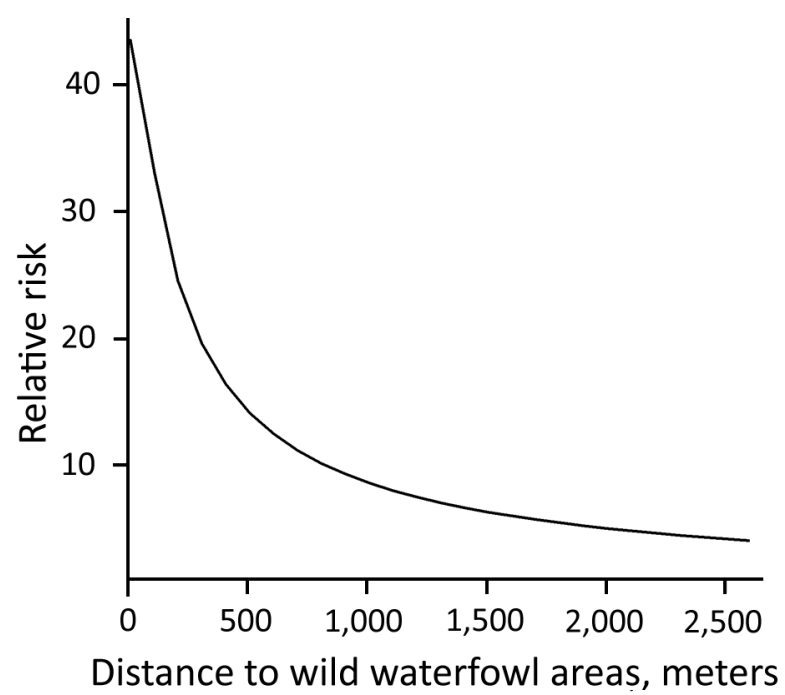

Figure 3. Relative risk for introduction of low pathogenicity avian influenza virus into meat-turkey farms, the Netherlands, 20072013. No difference in risk was observed between surveillance years. For the estimation of the relative risk as a function of distance to wild waterfowl areas, distance to medium-sized waterways (3-6 m wide) was kept constant. 
emerge after an LPAIV $\mathrm{H} 5 / \mathrm{H} 7$ introduction in poultry after varying lengths of time (8). If a notifiable LPAIV subtype infects a farm and later spreads to other farms before detection, the risk increases for mutation to HPAIV (35). Therefore, the sooner an introduction is detected, the sooner restrictive measures can be applied to contain the infection, ideally even to the index farm. Early detection and removal of infected poultry will help lower viral replication rounds.

Surveillance programs are important tools to prevent new HPAIV outbreaks. In the Netherlands the avian influenza surveillance program is much more intense than required by the European Union (9). Frequent sampling of high-risk poultry farms may help reduce the risk for transmission between farms $(31,36)$. Based on expected risk factors for introduction, outdoor-layer farms (more contact with wild birds) and meat-turkey farms (higher susceptibility) are tested more frequently than other poultry farms. The results of our study indicate that duck farms also should be tested more frequently; passive surveillance will not easily detect LPAIV introductions in ducks because LPAIV will not cause observable clinical signs in them. Furthermore, it is clear that we should target surveillance not only toward PT, but also on location (e.g., within $500 \mathrm{~m}$ of waterways, wild bird areas, or both). In addition, there could be a discouraging strategy for settlement of new poultry farms in high-risk areas.

This study was funded by the Dutch Ministry of Economic Affairs (Avian Influenza and Newcastle disease project WOT-01-003-012) and supported by the Veterinary Epidemiology and Risk Analysis project WOT-01-001-004.

Dr. Bouwstra was a project leader of avian influenza and Newcastle disease at Wageningen Bioveterinary Research, Lelystad, the Netherlands, at the time of the study and currently is head of the poultry health department, GD Animal Health, Deventer. Her research interests are notifiable animal diseases and One Health.

\section{References}

1. Webster RG, Bean WJ, Gorman OT, Chambers TM, Kawaoka Y. Evolution and ecology of influenza A viruses. Microbiol Rev. 1992; 56:152-79. PMID: 1579108

2. Koch G, Elbers ARW. Outdoor ranging of poultry: a major risk factor for the introduction and development of high-pathogenicity avian influenza. NJAS - Wageningen Journal of Life Sciences . 2006;54:179-94. https://doi.org/10.1016/S1573-5214(06)80021-7

3. Swayne DE, Halvorson DA. Influenza. In: Saif YM, Barnes HJ, Glisson JR, Fadly AM, McDougald LR, Swayne DE, editors. Diseases of poultry. 11th ed. Ames (IA): Iowa State University Press; 2003. p. 135-60.

4. World Organization for Animal Health. Avian influenza (infection with avian influenza viruses). In: OIE manual of diagnostic tests and vaccines for terrestrial animals [cited $2017 \mathrm{Feb} 13]$. http://www.oie.int/fileadmin/Home/eng/Health_standards/ tahm/2.03.04_AI.pdf

5. Elbers A, Knutsson R. Agroterrorism targeting livestock: a review with a focus on early detection systems. Biosecur Bioterror.
2013;11(Suppl 1):S25-35. http://dx.doi.org/10.1089/ bsp. 2012.0068

6. Capua I, Munoz O. Emergence of influenza viruses with zoonotic potential: open issues which need to be addressed. A review. Vet Microbiol. 2013;165:7-12. http://dx.doi.org/10.1016/ j.vetmic.2013.01.044

7. Gilbert M, Xiao X, Domenech J, Lubroth J, Martin V, Slingenbergh J. Anatidae migration in the western Palearctic and spread of highly pathogenic avian influenza H5NI virus. Emerg Infect Dis. 2006;12:1650-6. http://dx.doi.org/10.3201/ eid1211.060223

8. Alexander DJ. Should we change the definition of avian influenza for eradication purposes? Avian Dis. 2003;47(Suppl):976-81. http://dx.doi.org/10.1637/0005-2086-47.s3.976

9. European Commission. Commission decision 2007/268/EC of 13 April 2007 on the implementation of surveillance programmes for avian influenza in poultry and wild birds to be carried out in the Member States and amending decision 2004/450/EC. Official Journal of the European Union. 2007;115:2003.

10. Gonzales JL, Elbers ARW, Bouma A, Koch G, de Wit JJ, Stegeman JA. Low-pathogenic notifiable avian influenza serosurveillance and the risk of infection in poultry - a critical review of the European Union active surveillance programme (2005-2007). Influenza Other Respir Viruses. 2010;4:91-9. http://dx.doi.org/10.1111/j.1750-2659.2009.00126.x PMID: 20167049

11. Gonzales JL, Stegeman JA, Koch G, de Wit JJ, Elbers ARW. Rate of introduction of a low pathogenic avian influenza virus infection in different poultry production sectors in the Netherlands. Influenza Other Respir Viruses. 2013;7:6-10. http://dx.doi.org/10.1111/ j.1750-2659.2012.00348.x PMID: 22376126

12. Elbers ARW, Koch G, Bouma A. Performance of clinical signs in poultry for the detection of outbreaks during the avian influenza A (H7N7) epidemic in the Netherlands in 2003. Avian Pathol. 2005;34:181-7. http://dx.doi.org/10.1080/03079450500096497

13. Van der Goot J, Verhagen J, Gonzales J, Backer J, Bongers J, Boender GJ, et al. Laag pathogene aviaire influenza virus infecties op pluimveebedrijven in Nederland. CVI rapport 12/CVI0036 [cited 2016 Oct 14]. https://www.wageningenur.nl/upload_ $\mathrm{mm} / 9 / 3 / 3 / \mathrm{c} 49$ eea5e-dc40-4163-9ed8-3222e17c7c8a LPAIoppluimveebedrijveninNL.pdf

14. Fouchier RAM, Olsen B, Bestebroer TM, Herfst S, van der Kemp L, Rimmelzwaan GF, et al. Influenza A virus surveillance in wild birds in northern Europe in 1999 and 2000. Avian Dis. 2003;47 (Suppl):857-60. http://dx.doi.org/10.1637/0005-2086-47.s3.857

15. Olsen B, Munster VJ, Wallensten A, Waldenström J, Osterhaus ADME, Fouchier RAM. Global patterns of influenza a virus in wild birds. Science. 2006;312:384-8. http://dx.doi.org/ 10.1126/science. 1122438

16. Martin SW, Meek AH, Willeberg P. Disease causation. In: Veterinary epidemiology, principles and methods. Ames (IA): Iowa State University Press; 1987. p. 121-48.

17. Munster VJ, Veen J, Olsen B, Vogel R, Osterhaus AD, Fouchier RA. Towards improved influenza A virus surveillance in migrating birds. Vaccine. 2006;24:6729-33. http://dx.doi.org/10.1016/ j.vaccine.2006.05.060 PMID: 16806601

18. Si Y, de Boer WF, Gong P. Different environmental drivers of highly pathogenic avian influenza $\mathrm{H} 5 \mathrm{~N} 1$ outbreaks in poultry and wild birds. PLoS One. 2013;8:e53362. http://dx.doi.org/10.1371/ journal.pone. 0053362

19. Gilbert M, Pfeiffer DU. Risk factor modelling of the spatiotemporal patterns of highly pathogenic avian influenza (HPAIV) H5N1: a review. Spat Spatio-Temporal Epidemiol. 2012;3:173-83. http://dx.doi.org/10.1016/j.sste.2012.01.002

20. Stallknecht DE. Ecology and epidemiology of avian influenza viruses in wild bird populations: waterfowl, shorebirds, pelicans, 
cormorants, etc. In: Swayne DE, Slemons RD, editors. Proceedings of the 4th International Symposium on Avian Influenza; 1997 May 28-31; Athens Georgia. Jacksonville (FL): American Association of Avian Pathologists; 1998. p. 61-7.

21. Fouchier RAM, Osterhaus ADME, Brown IH. Animal influenza virus surveillance. Vaccine. 2003;21:1754-7. http://dx.doi.org/ $10.1016 / \mathrm{S} 0264-410 \mathrm{X}(03) 00067-7$

22. Elbers ARW, Fabri TH, de Vries TS, de Wit JJ, Pijpers A, Koch G. The highly pathogenic avian influenza A (H7N7) virus epidemic in the Netherlands in 2003-lessons learned from the first five outbreaks. Avian Dis. 2004;48:691-705. http://dx.doi.org/ $10.1637 / 7149$

23. Fouchier RA, Schneeberger PM, Rozendaal FW, Broekman JM, Kemink SA, Munster V, et al. Avian influenza A virus (H7N7) associated with human conjunctivitis and a fatal case of acute respiratory distress syndrome. Proc Natl Acad Sci U S A. 2004;101:1356-61. http://dx.doi.org/10.1073/pnas.0308352100

24. Bouwstra R, Heutink R, Bossers A, Harders F, Koch G, Elbers A. Full-genome sequence of influenza A(H5N8) virus in poultry linked to sequences of strains from Asia, the Netherlands, 2014. Emerg Infect Dis. 2015;21:872-4. http://dx.doi.org/10.3201/ eid2105.141839

25. Bouwstra RJ, Koch G, Heutink R, Harders F, van der Spek AN, Elbers ARW, et al. Full genome sequence of HPAI H5N8 outbreak strains provide evidence for four separate introductions and one between-poultry farm transmission in the Netherlands, 2014. Euro Surveill. 2015;20:21174. http://dx.doi.org/10.2807/1560-7917. ES2015.20.26.21174

26. Tumpey TM, Kapczynski DR, Swayne DE. Comparative susceptibility of chickens and turkeys to avian influenza A H7N2 virus infection and protective efficacy of a commercial avian influenza H7N2 virus vaccine. Avian Dis. 2004;48:167-76. http://dx.doi.org/10.1637/7103

27. Mundt E, Gay L, Jones L, Saavedra G, Tompkins SM, Tripp RA. Replication and pathogenesis associated with H5N1, H5N2, and H5N3 low-pathogenic avian influenza virus infection in chickens and ducks. Arch Virol. 2009;154:1241-8. http://dx.doi.org/10.1007/ s00705-009-0437-2

28. Hernández-Jover M, Schemann K, Toribio JA. A cross-sectional study on biosecurity practices and communication networks of poultry exhibition in Australia. Prev Vet Med. 2013;110:497-509. http://dx.doi.org/10.1016/j.prevetmed.2012.12.012
29. Ssematimba A, Hagenaars TJ, de Wit JJ, Ruiterkamp F, Fabri TH, Stegeman JA, et al. Avian influenza transmission risks: analysis of biosecurity measures and contact structure in Dutch poultry farming. Prev Vet Med. 2013;109:106-15. http://dx.doi.org/10.1016/j.prevetmed.2012.09.001

30. Van Steenwinkel S, Ribbens S, Ducheyne E, Goossens E, Dewulf J. Assessing biosecurity practices, movements and densities of poultry sites across Belgium, resulting in different farm risk-groups for infectious disease introduction and spread. Prev Vet Med. 2011;98:259-70. http://dx.doi.org/10.1016/ j.prevetmed.2010.12.004

31. Gonzales JL, Boender G-J, Elbers ARW, Stegeman JA, de Koeijer AA. Risk based surveillance for early detection of low pathogenic avian influenza outbreaks in layer chickens. Prev Vet Med. 2014;117:251-9. http://dx.doi.org/10.1016/ j.prevetmed.2014.08.015

32. Kampichler C, van Turnhout CAM, Devictor V, van der Jeugd HP. Large-scale changes in community composition: determining land use and climate change signals. PLoS One. 2012;7:e35272. http://dx.doi.org/10.1371/journal.pone.0035272

33. Van der Jeugd HP, Eichhorn G, Litvin KE, Stahl J, Larsson K, van der Graaf AJ, et al. Keeping up with early springs: rapid range expansion in an avian herbivore incurs a mismatch between reproductive timing and food supply. Global Change Biology. 2009;15:1057-71. http://dx.doi.org/10.1111/ j.1365-2486.2008.01804.x

34. Van Eerden MR, Drent RH, Stahl J, Bakker JP. Connecting seas: western Palaeartic continental flyway for water birds in the perspective of changing land use and climate. Global Change Biology. 2005;11:894-908. http://dx.doi.org/10.1111/ j.1365-2486.2005.00940.x

35. Alexander DJ. An overview of the epidemiology of avian influenza. Vaccine. 2007;25:5637-44. http://dx.doi.org/10.1016/ j.vaccine.2006.10.051

36. Comin A, Stegeman A, Marangon S, Klinkenberg D. Evaluating surveillance strategies for the early detection of low pathogenicity avian influenza infections. PLoS One. 2012;7:e35956. http://dx.doi.org/10.1371/journal.pone.0035956

Address for correspondence: Armin R.W. Elbers, Wageningen Bioveterinary Research, PO Box 65, 8200 AB, Lelystad, the Netherlands; email: armin.elbers@wur.nl

\section{EID Podcast: Backyard Poultry}

Backyard poultry flocks have increased in popularity concurrent with an increase in live poultry-associated salmonellosis (LPAS) outbreaks. In the United States, live poultry-associated salmonellosis outbreaks have been documented since 1955. Historically, these outbreaks involved young children, occurred in the spring months around Easter, and were associated with birds obtained as pets. Baby poultry were often dyed bright colors, making them more attractive to young children. Currently, public health officials are identifying LPAS outbreaks linked to backyard poultry flocks that are affecting adults and children. The first multistate outbreak where the association with backyard flocks was recognized occurred in 2007. 